\title{
On Intellectual Property Right Protection of Hyperlinks Infringement in China
}

\author{
Zehua Feng a \\ Doctoral Candidate of Graduate School and School of Marxism, Chinese Academy of Social Sciences, 102488 Beijing, China
}

\begin{abstract}
Hyperlink technology is an important technology for the dissemination of information in era of internet. With the rapid development of the network economy, various types of hyperlink technology are applied more frequently. Website operators also pay more attention to the ownership of their own network information resources and the protection of commercial interests. From the point of view of the protection of hyperlink technology, it has been regarded as an intellectual property right. Therefore, starting from different types of hyperlink technology and combining with the existing Copyright Law, Trademark Law and Anti-Unfair Competition Law, this paper reiterates the principles and standards of liability fixation for hyperlink infringement, which can provide countermeasures for website operators to resolve related infringement disputes.
\end{abstract}

\section{The nature of the hyperlink behavior and the reasons for the dispute}

Generally speaking, hyperlink technology refers to the information acquisition technology that can be freely accessed between different pages and columns by means of text, graphics, instructions and other media, and can establish links between different parts of the same page or between different pages. In European and American societies, hyperlink technology has been regarded as an intellectual property right.

\subsection{Types of hyperlinks}

According to the web links technology, hyperlinks can be classified into three types.

First, normal web links. In general, hyperlinks are normal links. The normal links can be divided into homepage links and paging links (it also known as deep links) according to the subjective purpose and linking mode of the linker. As the name implies, in the home page links, the builder of web links is guiding the website visitors (hereinafter referred to as visitors) to the home page of other websites, and its address bar still retains the original website, its legal risk is low. The deep links discussed in the intellectual property field refer to the way that the builder of web links bypasses the home page of the website and goes directly to the interface they want to use (usually the secondary pages of the website), and still displays the builder's address in the bar of the page, which will undoubtedly mislead visitors and make them unable to distinguish. This situation causes the confusion that who is the originator of website content, which affect the interests of original website operators.
Second, embedded web links. In the embedded links, the builder of web links displays the contents of the linked pages in his own pages through web links and the page address bar displays the builder's website address, so that visitors cannot perceive the contents of the pages from other pages [1].

Third, visual frame links [2]. Embedded and framed links also belong to their branches. In essence, they belong to a kind of embedded links. The technical feature of embedded links is that the windows of the linked websites are divided into several small windows (In other words, it can display multiple websites at the same time). Visitors cannot distinguish the real address of the pages they browse.

The above three types of hyperlinks are prone to causing legal disputes, especially in the form of deep links, the practice of skipping the permission of operator of the chained websites is equal to forcibly setting ticket fee points at the entrance of private gardens without the authorization of its owner in the real world to seek benefits. However, many commercial interests in the real world are not directly reflected by the number of clicks.

\subsection{Causes of disputes easily by hyperlink Technology}

Generally speaking, the owner of the website sued the person who had created web links without permission, mainly for three reasons. First, the most important source of revenue in website is advertising. In the Internet world, advertising revenue is directly depended on the number of visitors and clicks. builder of web links intentionally adopt the technology of hyperlink to skip the real websites (domain names) of the linked pages, which will

$\bar{a}$ Corresponding author: maofengren $@ 163 . c o m$ 
lead to a direct reduction in the number of visits to the original websites and advertising clicks as well as directly affect their revenue. Secondly, some websites often use reverse counterfeiting when setting up links-to keep their own domain names on the original websites to mislead visitors, so that they have the illusion that the fake web pages is the real one. If the fake website gets bad evaluation, these negative contents can be added to the original website, damaging its goodwill. For example, a non-governmental IELTS training organization, in order to promote its credibility, links many parts of its website to the pages of the IELTS official website without permission or license. If the organization is not well managed and its reputation is impaired, it will also affect the credibility of the IELTS training center. Thirdly, unlawfully setting up hyperlinks without consent by the owner of web sites is obviously full of commercial hostility, suspicion of unfair competition by hitchhiking and infringement of the original owner's right.

In short, many websites in order to enhance their influence, often with a considerable number of websites exchange links. For one thing, visitors can clearly see the changes of domain name by clicking on the link column. Naturally, there will be no confusion about the ownership of the content in the website. For another, this way of exchanging friendship links is to get the consent of both web page owners, which is naturally different from the complex legal consequences caused by unauthorized use. The intellectual property disputes caused by hyperlinks discussed in this paper mainly focus on the way of deep links, such as those who set up hyperlinks without the consent of website owner, bypassing the home page of original websites, but still retain their own domain name or deliberately hitchhiking behavior.

\section{Empirical analysis: the principle of imputation for hyperlinks Infringement}

Academics and practitioners have basically formed a consensus on the principle of liability for hyperlink infringement [3]. The following two typical cases reflect this consensus.

\subsection{Copyright infringement case of Beijing seven Color Rainbow Advertising Co., Ltd. v. Zhejiang Taobao Network Co., Ltd}

In 2011, in the case of copyright dispute between Beijing Seven Color Rainbow Advertising Co., Ltd. (hereinafter referred to as Rainbow) and Zhejiang Taobao Network Co., Ltd. (hereinafter referred to as Taobao), the defendant, Taobao website, such as "Taobao Portal, Women, Flower Marriage", and it contains 18 pictures of the Rainbow's claims. In the meantime, the IP address bar of the web page that appears after clicking on that column is "http://taobao.onlylady.com", as well as the words "copyright2003-2009, copyright TAOBAO.COM" are displayed below these pages. The plaintiff, Rainbow Company, decided that Taobao had infringed upon its work by disseminating it without its permission, so it sued the court. Taobao's defense is that it only links the page content of the third-party website by means of iframe (i.e. embedded links), in other words, its page content is provided by the third-party website, and it also disconnects the corresponding links after the lawsuit. Therefore, the court should use the "Safe Harbor Rules" to determine that Taobao does not constitute infringement The court held that the defendant Taobao had the right to decide the content, columns and sections of the web pages involved. Therefore, Taobao Company should be responsible for the legitimacy of the content of the website to review the obligation, and it should be responsible for the tort.

In this case, the court interpreted the legal nature of iframe links in detail, further affirming the qualitative basis of the "User Standard Theory". The exceptions to the "Safe Harbor Rules" and the subjective fault of the defendant (builder of web links) are classically expounded: Safe Harbor Rules is subjectively only applicable to the network service intermediaries who are not aware of the infringement facts in the dissemination of works. In the process of providing storage space, search service and link service, network service middlemen may not refer to the Safe Harbor Rules if their purpose is to use the works of the copyright owner to pursue certain commercial interests, such as click volume and promotion of related products. In the process of providing storage space or search service or link service, the intermediary shall provide relevant network services and shall not apply "Safe Harbor Rules" if they know that the infringement of copyright has occurred or should know that the infringement of copyright may occur.

Looking back on the judgment of this case, although the court ruled out the application of the "Safe Harbor Rules" by the "User Standard Theory", the judgment basis of the defendant's legal liability is still inseparable from the subjective malignant conviction of the defendant In other words, the defendant has a complete decision on the contents, columns, sections and other settings of the web pages involved. The act of setting the plaintiff's address as his own web site does not meet the requirements of subjective ignorance or should be known, and is sufficient to presume that he has subjective malice. The defendant take the name of web links as a cover, using iframe's link mode, in fact this plagiarism cannot be justified.

\subsection{Infringement case of Shenzhen Qvod Technology CO., LTD. for Information transmission right}

The plaintiff, China Film Co., Ltd. (Hereinafter referred to as China Film) claimed that the function of the software from the company of Shenzhen Kuaibo Technologies Co., Ltd. (Hereinafter referred to as Kuaibo) infringed on the right to disseminate the information of its work in Internet, so it filed a lawsuit in court. The plaintiff claims that keywords (such as movie "I do") are typed into the software search box of the defendant's Player software would direct to a third-party search site, which displays the search results for all the resources and 
is a complete video of the film involved. At the same time, the above search results can be linked to the film broadcasting site. The film copyright is owned by the Chinese Film Company but not licensed.

After investigation, the court held that although the defendant's claim of search engine integration did not link to infringing works, it directed the users to a thirdparty search site, which not only limited the search object to specific types of documents, but also limited the search scope to specific sites. Therefore, it can be concluded that the defendant and the linking web sites jointly implemented the search. So the defendant has subjective fault for linking infringement works involved. Finally, the court ordered the defendant to stop the infringement and compensate the plaintiff for the loss.

Unlike the previous case, Kuaibo in this case has not taken the technology of visual frame link to take possession of the content of the linked website. However, the search link service provided by Kuaibo also exists in the situation of knowing or should know subjectively without the consent of the linked website. Although the Kuaibo and third-party search websites provided link search freely, it did not conceal the domain name of China Film. Subjectively, their behavior of skipping the home page of China Film and reaching the website of a film directly does not rule out its desire for film viewers to think that this part of the film is all their intentions. Therefore, Kuaibo is still liable for its own faults, including subjectively unauthorized use and prudently scrutinized obligations.

\section{Regulation of hyperlink behavior in intellectual property law}

The infringement caused by hyperlink technology needs to be discussed in two aspects. First, the direct infringement of other people's copyright, in other words, it acts that directly hinder copyright owners from exercising the rights of copy, distribution, adaptation and dissemination in Internet, which are becoming more and more rare in practice (the builder of web links often affect the dissemination effect interests of the original website when the third-party websites are involved). Second, through the assistance, connivance and joint participation of third-party websites, the right to disseminate information on the Internet has been infringed [4], just like the second cases mentioned above. In practice, the defendant (the builder of web links) often invokes subjective unknowns (when a third party website involved) and the "Safe Harbor Rules" to defend the infringement accusations. Then how do the various departments of the legal system for intellectual property judge the infringement?

\subsection{Copyright law protection is still the best choice although there are some deficiencies}

Through deep links, the information and materials of the original website may not necessarily be stored on the server of the builder of web links, because the builder usually provides a guide but does not directly copy the contents of the original website. Therefore, it is difficult to define that this act infringes the owners' copyright to reproduce and distribute. Although the Copyright Law stipulates the right to disseminate information on the Internet, it does not specify the form of infringement.

As a special law of the Copyright Law, Article 23 of the Regulations on the Protection of the Right to Information Dissemination in Internet(RPRIDI) stipulates that Internet service providers afford search or link services for the customers, after receiving notice from the obligee, disconnect the linkages of works, performances, audio and video recordings that are infringed upon by the provisions of this Regulation, it shall not be liable for compensation. However, those who know or should be aware of the infringement of the works, performances, audio-visual recordings that are linked to original websites shall bear joint liability for their tort. This regulation directly establishes the imputation principle of linking service provider, but the first half of the provisions undoubtedly give the builder of web links the opportunity to take advantage of its loophole. Videlicet, after the builder has completed the malice behavior of infringement and seized the interests, there is still the opportunity to prove that he or she is subjectively unknowing or objectively disconnecting the link in order to weasel out of obligation. Since the predication of subjective fault will directly determine the liability of tort, the criteria for judging the subjective intent of the builder of web links is also particularly important. Article 23 clarifies that although builders who known or ought to be known their infringement is still liable, the criteria of "know" and "ought to know" are not clearly defined, which is difficult to realize in judicial practice and easily leads to excessive discretion of the court. It is possible to overload the responsibility of the builders or even make the rights of the owner of original websites damaged without relief.

\subsection{Other protection: the coverage is not wide and the connection between the articles is unbalance}

Article 36, paragraph 3 of the Tort Liability Law in China stipulates that if a network service provider knows that customers has infringed upon others' civil rights and interests by using the network service and has not taken necessary measures, it shall bear joint liabilities with its customers. As a law with general regulation, the Tort Liability Law does not adopt the same criteria of "know" or "ought to know" as RPRIDI, so its burden of proof for potential infringers can be said to be looser. Some scholars advocate using the Trademark Law to protect domain names and regulate hyperlinks. However, the essence of a trademark is to help consumers differentiate between various goods or services, while a domain name is the address where a network user enters the cyberspace to enjoy different products or services. As a kind of network technology, the characteristics and functions of hyperlinks cannot be exactly equal to domain names. Therefore, we do not advocate this means of protection [5]. 
Within the existing legal framework of China, the Anti-Unfair Competition Law is regarded as a powerful supplement to the Copyright Law and the Trademark Law. Undoubtedly, the act of setting up deep links without permission does have some benefits for the owners of original websites, but the act of retaining its original domain name without authorization may mislead visitors into the illusion that the web page they browsing belongs to the original website, whose behavior has met the requirements of confusion in legal practices. However, the Anti-Unfair Competition Law is mainly used to regulate commercial competition. The competition between linked websites is not obvious in real life. This has fallen into the strange circle of regarding hyperlinks as trademarked domain names, and the scope of protection is not comprehensive. On the contrary, under the premise that RPRIDI has made clear the attitude towards the link behavior, it is more appropriate for the behavior of hyperlink technology to be regulated by special regulations.

\section{The fault determination standard to the builders of web links: a unified evaluation path of subjective and objective views}

As for the fault determination standard of the builders of web links, we must take the interests of the builders of web links and the owners of original websites into account at the same time, seeking a unified standard in the balance of interests and relief. According to the four elements (i.e. subject elements, subjective elements, nonintervention elements and assistance relief elements) established by the "Safe Harbor Rules", we can easily find that the subjective fault of the builders is often inseparable from other objective criteria. In other words, when judging whether the builders is subjectively "fault" (i.e. whether he knows or should know that his actions are illegal), we can discuss it in two situations. First, in the absence of third-party website intervention, we can determine that the builders have subjective intention if the linking website is used to avoid the original websites or tampered with the domain name. Of course, the builders positively cooperate with the act of cutting links after the event, still being reserved the opportunity of exemption from liability for the link setting behaviors. Secondly, when third-party websites are involved, it is difficult for judges to decide whether the builders has subjective intent on the link behavior. Coupled with the exemption of the "Safe Harbor Rules", the interests of the original websites may not be protected. At this time, we need subjective evaluation standard, identifying the fault of the builders. If the builders does not edit, store or modify the linking services provided by the third party websites in any form, and any evidences to prove that he or she knows the ownership of the contents of the original websites, it is not appropriate to identify his or her subjective fault, in case the alienation of the principle of "Fault Liability" to the principle of "Fault Promotion", thereby improperly aggravates the burden of proof of the builders. The development of hyperlink technology undoubtedly provides great convenience for the replication and dissemination of Internet information. The hyperlink technology from one page to another page should be able to build a convenient bridge between customers and linked pages and is conducive to the development of the Internet information industry.

\section{Conclusion}

Faced with more and more infringement disputes of network hyperlink, the legal systems also needs to respond to them in a timely manner. The comprehensive protection system centered on RPRIDI has not yet fully clarified the basis for the liability of unauthorized behaviors in hyperlink. We can adhere to the unified evaluation mechanism of subjective and objective standards on this basis, handling all kinds of disputes in judicial practice, so as to balance the interests of all parties in hyperlink relations. The protection from copyright law is still the most effective and appropriate means to regulate the legal relationship involved in the behaviors of hyperlinks. Nevertheless, we must clarify the judgment principles of "Subjective Fault" of the builders if we want to guide the judicial work in practice more effectively.

\section{References}

1. Li Zhuo, Probe into the Infringement of Intellectual Property Rights on Hyperlinks on the Internet, Intelligence Journal, p.71, No.5, Vol.23 (2004).

2. Jiao Wenming, Legal Regulations on Hyperlink Infringement, Journal of Nanjing University (Philosophy, Humanities and Social Sciences), p.128, No.5, Vol.38(2001).

3. He Xiaobing, Legal Issues on Infringement of Internet Links, Science and Technology and Law, p.694, No.4, Vol. 92(2011).

4. Zheng Chengsi, Intellectual Property Literature, Beijing: China University of Political Science and Law press, pp. 174-176(1999).

5. Xu Songlin, Criminal Regulations on Deep Linking Behavior of Video Search Websites. Intellectual Property Rights. pp.26-31, No. 11, Vol.28(2014). 